United States Department of Agriculture Agricultural Research Administration Bureau of Entomology and Plant Quarantine

\title{
A LEAF PUNCH FOR SAMPLING INSECTICIDE RESIDUES ON FOLIAGE
}

\author{
By Jack E. Fahey and Harold W. Rusk \\ Division of Insecticide Investigations
}

For studying residues of insecticidal dusts or sprays on foliage it is desirable to have a simple, easily operated device for obtaining a known area of leaf. Several such implements are described in the literature. Fulton (1) gives specifications for a leaf punch employed in the study of sulfur residues on citrus foliage. Lathrop et al. (2) have described a method of cutting known areas of leaf surface for residue analysis. A. W. Cressman of this Bureau has described in personal correspondence a leaf punch which he has used for studying oil residues on foliage. It was designed by L. H. Dawsey and is very similar to that employed by the authors. It is therefore with no thought of originality, but rather to describe a useful tool that has not been described in the literature, that this paper is prepared. A leaf punch has been designed which will cut a leaf disc 0.75 inches in diameter and will deposit the disc in a samplecollecting bottle. The punch with sample-collecting bottle attached weighs approximately 1 pound and can be easily operated with one hand leaving the other free to guide the leaf to be sampled into the cutting area.

The sampling device was constructed from a pair of pliers with parallel-action jaws (Bernard pliers). To the jaws of these pliers were attached (by brazing) $1 / 4$-inch steel plates $11 / 2$ inches by $21 / 3$ inches which had previously been fitted, one with a $3 / 4$-inch.punch and the second with a die plate. Alignment of the punch and die plate is maintained by two guides between the plier jaws; these guides also act as retainers for coil springs which provide a return action for the pliers. Attached to the bottom of the plier jaw carrying the die plate is a screw cap for a 2-ounce sampling bottle which catches and retains the leaf discs cut by the punch and die.

Two views of the punch are shown in figure 1 .

The advantages of this device over similar apparatus are primarily simplicity and convenience. The steel punch and die plate cut perfect leaf discs and, when made of tool steel, will wear indefinitely. The leaf disc is forced through the die plate by the punch and falls automatically into the sampling container, which is readily attached to or removed from the punch by a simple twist. 


\section{Literature Cited}

(1) Fulton, Robert A.

1942. A leaf punch for use in insecticidal residue studies. Bur. Ent. and Plant Quar. ET-189, 2 pp., illus.

(2) Lathrop, F. H., Plummer, Bernie E., and Dirks, C. O.

1944. A simplified method of sampling known areas of apple leaves for chemical analysis. Jour. Econ. Ent. 37: 294-295, illus.

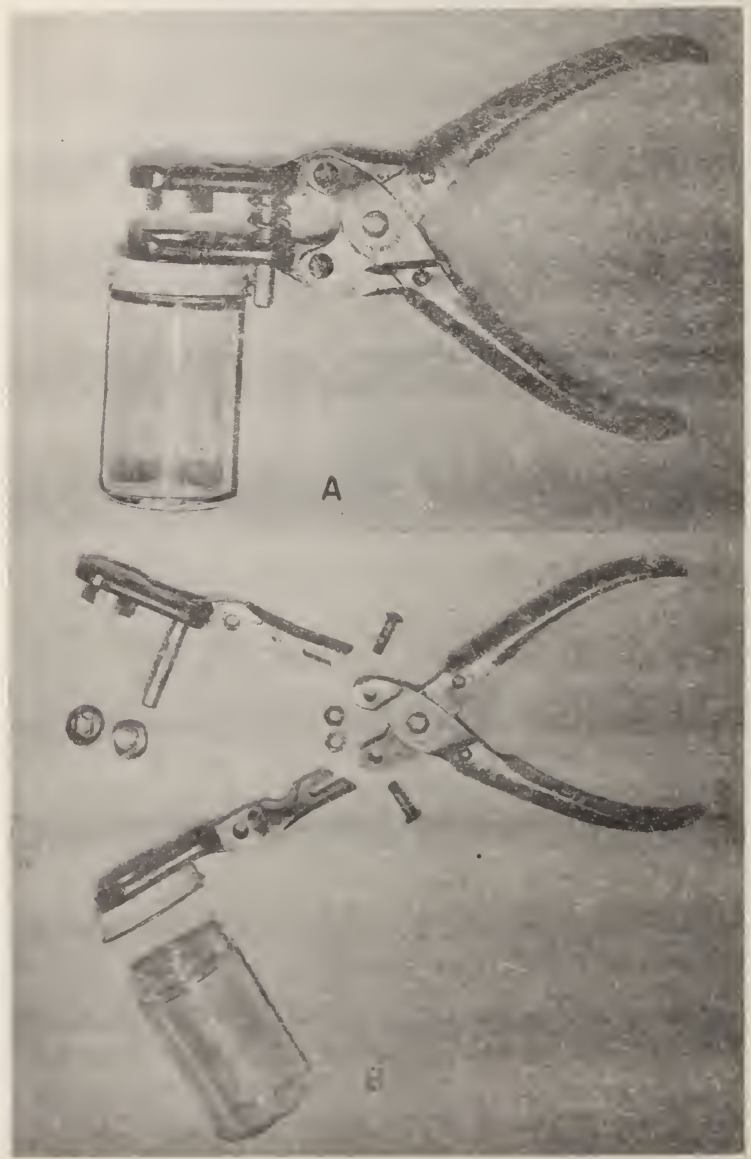

Figure 1.--Foliage-sampling machine: $\mathrm{A}$, Assembled; $\mathrm{B}$, dismantled to show structural parts. 